\title{
PROCESSOS AVANÇADOS DE OXIDAÇÃO DE COMPOSTOS FENÓLICOS EM EFLUENTES INDUSTRIAIS
}

\author{
Jaildes Marques Britto e Maria do Carmo Rangel* \\ Instituto de Química, Universidade Federal da Bahia, Campus Universitário de Ondina, 40170-280 Salvador - BA, Brasil
}

Recebido em 20/7/06; aceito em 30/3/07; publicado na web em 14/1/08

\begin{abstract}
ADVANCED OXIDATION PROCESS OF PHENOLIC COMPOUNDS IN INDUSTRIAL WASTERWATER. In an effort to minimize the impact on the environment, removal of pollutants, such as phenolic compounds, from the industrial wastewater has great importance nowadays because of the high toxicity and low biodegradability of these compounds. This work discusses the different methods to remove these compounds from industrial wastewater, showing their advantages and disadvantages. Advanced Oxidation Process (AOPs) are presented as a promising technology for the treatment of wastewater containing phenolic compounds. Among the AOPs, photolysis, photocatalysis and the processes based on hydrogen peroxide and on ozone are discussed with emphasis on the combined processes and the oxidation mechanisms.
\end{abstract}

Keywords: penol oxidation; Advanced Oxidation Process; copper catalyst.

\section{INTRODUÇÃO}

No início do século 21 a humanidade se deparou com o problema da escassez de água como uma ameaça para a saúde humana e a vida do planeta. A escassez ou falta de água afeta mais que $40 \%$ da população mundial, por razões políticas, econômicas e climáticas. Em paralelo, mais que $25 \%$ da população mundial sofre de problemas de saúde, ou de higiene, relacionados à água ${ }^{1}$. Apesar dos esforços institucionais para a melhoria da qualidade da água e da infra-estrutura sanitária, cerca de 1,1 bilhões de pessoas não têm acesso a um suprimento adequado de água e esgoto, especialmente em países da África, Ásia e América Latina.

Por outro lado, o uso doméstico e as atividades industriais, especialmente em países desenvolvidos, geram elevadas quantidades de resíduos e efluentes que são, muitas vezes, dispostos diretamente em cursos naturais e impactam consideravelmente o meio ambiente ${ }^{1}$.

Os efluentes de plantas industriais, tais como refinarias, gaseificadores de coque e plantas petroquímicas, freqüentemente contêm elevados teores de compostos orgânicos, entre eles os compostos fenólicos ${ }^{2,3}$. A toxicidade destes compostos, em ambientes aquáti$\cos$, tem sido bastante estudada e está bem estabelecido que a presença destes contaminantes, em níveis de ppm, afeta significativamente as propriedades organolépticas da água ${ }^{4,5}$. Outra característica indesejável destes contaminantes é o fato de que, no processo de cloração da água potável, a sua reação com cloro produz clorofenóis e policlorofenóis que são carcinogênicos ${ }^{6,7}$.

Alguns compostos fenólicos estão naturalmente presentes na água do mar, uma vez que alguns bromofenóis são produzidos por algumas espécies de algas vermelhas; entretanto, diversos estudos têm mostrado que a água poluída é a principal fonte de absorção de fenol por organismos aquáticos ${ }^{7}$.

Em efluentes industriais, podem ser encontrados mais de um tipo de poluente fenólico ${ }^{8}$. Aqueles que apresentam estruturas mais complexas são frequientemente mais tóxicos que o fenol ${ }^{3,4}$. Os cresóis, clorofenóis e resorcinol, por exemplo, são encontrados em efluentes industriais, mas não foram ainda caracterizados e monitorados de forma sistemática ${ }^{5}$.

A necessidade do restabelecimento das áreas contaminadas,

*e-mail: mcarmov@ufba.br evitando futuras contaminações, tem levado ao desenvolvimento de métodos para a remoção de fenol do ambiente aquático. O objetivo principal é alcançar uma completa mineralização do poluente a dióxido de carbono e água e, além disso, reduzir as concentrações de íons tais como os cloretos ou, ainda, reduzir a toxicidade dos compostos intermediários.

Com a publicação da Resolução CEPRAM 2113, em 1999, o limite de concentração de fenóis no efluente final, lançado pelas indústrias no meio ambiente, foi modificado de 100 para $10 \mathrm{mg} / \mathrm{L}$. A resolução CONAMA n 357, publicada em 18 de março de 2005, revogou a Resolução CONAMA 20/86 e define como padrão de lançamento para efluentes industriais o teor de $0,5 \mathrm{mg} / \mathrm{L}$ de fenóis totais, expresso como $\mathrm{C}_{6} \mathrm{H}_{5} \mathrm{OH}$.

Como a legislação ambiental e os padrões de qualidade de saúde tornam-se cada vez mais restritivos, surgem demandas para a definição de estratégias para o desenvolvimento de tecnologias limpas, melhoria dos processos existentes e desenvolvimento de sistemas industriais fechados de purificação e reciclagem de água ${ }^{2,9}$. Com estas ações, pretende-se buscar soluções para os problemas estabelecidos e se antecipar com relação a novas fontes poluidoras.

Neste contexto, o presente trabalho aborda os principais aspectos relativos à degradação e mineralização de compostos fenólicos em meio aquoso, através de processos de oxidação. $\mathrm{O}$ estudo pretendeu analisar criticamente os processos existentes em nível industrial e de laboratório, procurando-se identificar os mais eficientes e/ou promissores.

\section{A ORIGEM DOS COMPOSTOS FENÓLICOS NOS EFLUENTES INDUSTRIAIS E SEU IMPACTO AMBIENTAI}

Os efluentes de plantas industriais, tais como coquearias, refinarias de petróleo e produtoras de resinas, entre outros, freqüentemente contêm compostos fenólicos ${ }^{10}$.

As coquearias são responsáveis pela produção de gás e coque para aplicações metalúrgicas e outros produtos como benzeno, tolueno, antraceno e naftaleno, que apresentam inúmeras aplicações industriais e comerciais ${ }^{11}$. Nos fornos das coquearias, o carvão é convertido em coque que é utilizado na produção de ferro e aço, entre outras aplicações. O efluente aquoso gerado nas coquearias apresenta três origens principais: água usada para resfriamento do 
coque oriundo das retortas e fornos; efluente aquoso gerado durante o resfriamento e lavagem do gás produzido e, efluente aquoso formado durante o processo de purificação dos subprodutos do coque.

O efluente líquido gerado é altamente poluente, de difícil tratamento e apresenta em sua composição compostos amoniacais, cianetos e, especialmente, compostos fenólicos na faixa de concentração de 80 a $123 \mathrm{mg} / \mathrm{L}$. Ao serem dispostos em cursos de água, estes efluentes causam sérios problemas ambientais ${ }^{11}$.

No caso das refinarias de petróleo, o craqueamento catalítico em leito fluidizado gera efluentes contendo concentrações consideráveis de fenol (50-260 ppm massa) e concentrações comparáveis de íons sulfeto e amônia ${ }^{10}$.

Por outro lado, na indústria petroquímica, as unidades de pirólise produzem etileno a partir do craqueamento térmico da nafta a temperaturas superiores a $1000^{\circ} \mathrm{C}$, em presença de vapor d'água. Este processo também é conhecido como pirólise, que é a decomposição de um composto sob a ação exclusiva do calor ${ }^{12,13}$. A pirólise dos hidrocarbonetos presentes no gás natural, nafta ou gasóleo é economicamente uma das mais importantes reações usadas nas indústrias desde a década de $50^{14}$. Entretanto, a presença de compostos fenólicos, nos efluentes gerados nos processos de pirólise de hidrocarbonetos, foi identificada muito recentemente ${ }^{14}$.

A identificação da natureza das reações químicas envolvidas no processo de pirólise avançou pouco, em comparação aos avanços relacionados à tecnologia de construção de fornos de craqueamento e outros equipamentos. A decomposição pirolítica de hidrocarbonetos é uma das mais complexas reações químicas desses compostos ${ }^{14}$. A elevada temperatura do sistema reacional, a presença de compostos intermediários instáveis e a ocorrência de reações parciais paralelas e consecutivas constituem os principais fatores que conferem complexidade ao sistema reacional.

A formação de compostos aromáticos no processo de pirólise foi descrita pelo mecanismo inicialmente proposto pelos pesquisadores Wheeler e Wood em 1930, estudando efluentes gerados pelas unidades industriais. O mecanismo de reação formulado tem como rota principal a formação de anéis aromáticos e as reações Diels-Alder do butadieno com outras olefinas. Além das reações classificadas anteriormente, ocorrem reações de superfície, reações de mecanismo molecular, também do tipo Diels-Alder e reações de polimerização em fase gasosa ${ }^{13}$.

Todas as reações laterais originam os subprodutos do craqueamento térmico, sendo o principal deles a gasolina de pirólise, uma mistura de vários hidrocarbonetos aromáticos, parafinas e olefinas ${ }^{15}$. No processo industrial, os componentes condensados da gasolina são separados d'água proveniente do vapor, injetado juntamente com os reagentes, e estabilizados utilizando-se operações unitárias convencionais. Os compostos oxigenados formados no processo, entre eles os compostos fenólicos, concentram-se na fase aquosa por afinidade e, conseqüentemente, encontram-se presentes no efluente aquoso gerado neste processo. A formação de moléculas oxigenadas não é descrita na literatura através de mecanismos reacionais; entretanto, é prevista a partir da participação do vapor de água na reação de pirólise de hidrocarbonetos ${ }^{16}$.

$\mathrm{O}$ fenol, um dos contaminantes oxigenados presentes em efluentes industriais, é uma substância incolor e cristalina usada como desinfetante e na produção de várias resinas poliméricas, como por exemplo, a baquelite. Por ser muito solúvel em água, constitui-se em um sério contaminante para o meio ambiente $\mathrm{e}^{8,17}$.

A contaminação de compostos fenólicos em águas potáveis pode causar sérios problemas de saúde pública. A presença destes compostos em doses subletais afeta os sistemas nervoso e circulatório, com redução do crescimento de células sanguíneas ${ }^{4,5}$. Mesmo em concentrações extremamente baixas $(0,002 \mathrm{mg} / \mathrm{L})$, o fenol produz um sabor identificável na água. Esta característica constitui-se em problemas operacionais em cervejarias, destilarias e unidades de engarrafamento de água mineral.

Os compostos fenólicos também são tóxicos ao meio ambiente aquático, podendo provocar a morte de peixes, mesmo em concentrações na faixa de $1 \mathrm{mg} / \mathrm{L}$. Em concentrações inferiores a ppm, eles são tóxicos também a outras espécies biológicas, uma vez que destroem o delicado balanço ambiental aquático ${ }^{8}$. Elevadas concentrações de fenóis podem causar perturbação e serem tóxicas às bactérias usadas nos lodos ativados das unidades de tratamento de efluentes ${ }^{8}$.

Os efluentes industriais, geralmente, contêm mais que um tipo de poluente fenólico, sendo que aqueles com estruturas mais complexas são freqüentemente mais tóxicos que a molécula de fenol ${ }^{4}$.

\section{PROCESSOS DE TRATAMENTO DE EFLUENTES}

As principais tecnologias convencionais empregadas no abatimento de fenol em efluentes industriais são: o tratamento biológico, os processos de extração, o tratamento com carvão ativado, os processos térmicos, o arraste com ar ou a osmose reversa ${ }^{1,10}$.

No que diz respeito ao tratamento biológico, a tecnologia de lodo ativado é amplamente utilizada, especialmente em centrais de tratamento de efluentes industriais ${ }^{10,18}$. O método consiste na degradação de compostos orgânicos em tanques de lodo, com sistemas biológicos aeróbicos e anaeróbicos, monitorando-se continuamente a temperatura, a demanda química de oxigênio (DQO) e os contaminantes a serem degradados. A elevada toxicidade dos compostos fenólicos torna, entretanto, inconveniente a aplicação deste método em correntes com elevadas concentrações de fenóis, pois tais compostos são recalcitrantes à biodegradação e tóxicos aos microorganismos ${ }^{4}$, uma vez que concentrações acima de $70 \mathrm{mg} / \mathrm{L}$ de fenol são consideradas tóxicas à população microbial ${ }^{19}$.

A extração líquido-líquido, por sua vez, é uma tecnologia eficiente e economicamente viável na remoção e recuperação de fenol, em correntes nas quais este contaminante se encontra presente em concentrações superiores a $1 \%{ }^{21}$. Neste processo, um ou mais solutos são removidos de uma corrente líquida por transferência do soluto para uma segunda fase líquida, imiscível ou parcialmente miscível com a primeira. Uma vez que não se requer a vaporização da corrente, a extração pode ser conduzida a baixas temperaturas e, portanto, é um processo de separação aplicável a moléculas termo instáveis ${ }^{21}$. Entretanto, nos casos de sistemas com concentrações mais baixas de soluto, como é o caso de efluentes industriais contaminados com compostos fenólicos, o custo operacional de uma unidade de extração é muito elevado em função das utilidades requeridas e pode inviabilizar a sua aplicação ${ }^{22}$.

A adsorção com carvão ativado é uma técnica empregada, com sucesso, no tratamento de efluentes contaminados com baixas concentrações de compostos fenólicos, por ser eficiente e econômica. Em temperaturas de adsorção relativamente altas, longos tempos de contato e elevadas concentrações de oxigênio, os compostos fenólicos tendem a ser irreversivelmente adsorvidos na superfície do carvão. O processo apresenta, entretanto, a desvantagem de exigir uma etapa de regeneração, durante a qual o contaminante é concentrado na fase vapor. Além disso, o processo de adsorção não resolve o problema ambiental, uma vez que o resíduo gerado, freqüientemente, deve ser disposto no meio ambiente $e^{6,10,20}$.

Os tratamentos térmicos são os processos mais comuns e amplamente usados na remediação de águas contaminadas por compostos voláteis e podem envolver as operações de arraste com ar ou de extração ${ }^{19}$. A metodologia envolve a injeção de ar para dentro do aqüífero contaminado, a transferência dos contaminantes voláteis para a fase gasosa e sua separação por um sistema de ex- 
tração de vapor. Entretanto, esse processo apresenta baixa eficiência para a remoção de compostos fenólicos, usualmente de maior solubilidade em água ${ }^{19}$.

Outros processos tais como a floculação, precipitação ou osmose reversa requerem um tratamento posterior para a remoção do poluente e, portanto, apresentam aplicações limitadas ${ }^{1}$.

Existem métodos alternativos a estas técnicas já bem estabelecidos, que envolvem a oxidação de poluentes com reagentes como o ar ou o oxigênio em fase aquosa, tais como a oxidação supercrítica, a oxidação eletroquímica e o uso de permanganato de potássio, cloro, peróxido de hidrogênio ou ozônio. Dentre estas técnicas, os processos avançados de oxidação (AOP's) aparecem como os mais promissores para aplicação em água e solos contaminados, por promoverem a degradação total dos poluentes. Estas técnicas podem também levar à formação de contaminantes menos poluentes, usualmente compostos orgânicos oxigenados e ácidos de baixo peso molecular, sendo aplicáveis ao tratamento de águas contaminadas com baixas concentrações de poluentes ${ }^{1}$.

\section{PROCESSOS AVANÇADOS DE OXIDAÇÃO (AOP, "Advanced Oxidation Process")}

Os processos avançados de oxidação constituem uma classe especial de técnicas de oxidação apontadas como promissoras e que geralmente envolvem baixas temperaturas e pressões ${ }^{23}$. Diversos sistemas reacionais são empregados nos AOP's, mas em todos eles se produzem radicais livres hidroxilas $\left(\mathrm{OH}^{\bullet}\right)$. Estas espécies ativas reagem com as moléculas orgânicas rápida e indiscriminadamente, seja por adição à dupla ligação ou por abstração do átomo de hidrogênio em moléculas orgânicas alifáticas. $\mathrm{O}$ resultado é a formação de radicais orgânicos que reagem com oxigênio, dando início a uma série de reações de degradação que podem culminar em espécies inócuas, tipicamente dióxido de carbono e água ${ }^{19}$.

Os radicais hidroxilas $\left(\mathrm{OH}^{\bullet}\right)$ são tradicionalmente considerados como espécies ativas responsáveis pela decomposição de poluentes, graças ao seu potencial de redução padrão de $2,8 \mathrm{~V}$ em meio ácido. Esses compostos são capazes de oxidar quase todos os compostos orgânicos a dióxido de carbono, exceto os compostos orgânicos mais simples como os ácidos oxálico, maléico e a acetona. Estes compostos, produtos da oxidação de moléculas maiores, participam dos ciclos energéticos da maioria dos organismos vivos ${ }^{1}$.

Atualmente, a utilização de reagentes eletrogerados tais como o ozônio e o peróxido de hidrogênio tem aumentado bastante, em função da necessidade de tecnologias limpas no tratamento de efluentes ${ }^{24}$. Contudo, a aplicação das técnicas de AOP deve considerar o elevado custo dos agentes oxidantes utilizados e, portanto, deve ser aplicado em casos de substâncias refratárias aos tratamentos biológicos, que são mais econômicos. As AOP's são aplicáveis a sistemas cuja concentração do poluente não é muito elevada $(<5,0 \mathrm{~g} / \mathrm{L})$ aos quais outros processos de abatimento são inviáveis técnica ou economicamente ${ }^{23}$.

Vários processos de produção de radical hidroxila têm sido estudados e dentre os principais estão a fotólise, a fotocatálise e a oxidação com o ar, com peróxido de hidrogênio e ozônio, além dos sistemas combinados constituídos de oxidantes, adsorventes e catalisadores ${ }^{23}$.

\section{O processo da fotólise}

O uso da radiação ultravioleta tem sido avaliado no tratamento de resíduos, principalmente visando sua desinfecção ${ }^{22}$, e tem sido usada no tratamento de compostos orgânicos voláteis. A fotólise direta envolve a interação de luz com as moléculas, causando a sua dissociação em fragmentos.
Estudos recentes sobre a fotólise direta empregando radição ultravioleta mostraram a rápida degradação de poluentes, como os clorofenóis em soluções aquosas diluídas ${ }^{22}$. Por outro lado, a técnica mostra-se menos eficiente que os outros processos, em que a radiação é combinada com peróxido de hidrogênio ou ozônio, ou em que catalisadores homogêneos ou heterogêneos são empregados simultaneamente com a luz ${ }^{25}$.

\section{O processo de fotocatálise}

A fotocatálise é um processo alternativo para o tratamento de água poluída, visando a remoção de fenol através da neutralização do contaminante, sem deixar resíduos perigosos no meio ambien$\mathrm{te}^{26}$. O processo utiliza óxidos de um metal semicondutor como catalisador e oxigênio como agente oxidante. Muitos catalisadores foram testados com este propósito, mas, apenas o dióxido de titânio na forma de anatase apresenta atributos de elevada estabilidade, bom desempenho e baixo custo ${ }^{23}$.

A redução de custos também pode ser alcançada através da tecnologia solar. Em 2003, Gernjak e colaboradores investigaram o desempenho do sistema heterogêneo de dióxido de titânio e sistemas homogêneos do tipo foto-Fenton, usando luz solar no abatimento de uma mistura de compostos fenólicos. Os sistemas foram eficazes na degradação desses compostos, especialmente o sistema foto-Fenton e a conversão de fenol foi superior à redução do teor de carbono orgânico total. Em comparação com os experimentos utilizando fonte artificial de luz ultravioleta em laboratório, e com luz solar em planta piloto, o desempenho da luz solar com sistemas homogêneos foi superior, um fato que possibilita a sua aplicação futura em escala industrial ${ }^{27}$.

A fotocatálise apresenta muitas vantagens comparada com outras técnicas de oxidação, no que se refere ao meio ambiente, devido à inércia dos produtos utilizados no processo e pela possibilidade do uso da luz solar como fonte de radiação ultravioleta ${ }^{28}$. Entretanto, a aplicação destes procedimentos em escala industrial é bastante discutida, principalmente em função das desvantagens que derivam do seu caráter heterogêneo. Neste sentido, a dificuldade da penetração da radiação em um meio aquoso que contém uma fina suspensão de partículas opacas e a dificuldade na remoção dos fotocatalisadores, ao final do processo, constituem as principais desvantagens destes métodos. Com o intuito de contornar estes problemas, muitos trabalhos sobre a imobilização de semicondutores, em suportes como zeólitas, cerâmicas, sílicas, vidros, polímeros e outros têm sido desenvolvidos nos últimos anos ${ }^{19,26,29}$.

\section{O processo de oxidação com ar}

Diversos trabalhos científicos apresentaram técnicas alternativas ao processo biológico, para o abatimento de poluentes orgânicos em água. As técnicas de oxidação com ar ou com peróxido de hidrogênio foram bastante discutidas devido à importância desses métodos ${ }^{30}$.

Os processos usuais de oxidação de correntes aquosas com ar geralmente requerem elevadas temperaturas e pressões, para se obter uma alta conversão dos produtos mais tóxicos e refratários. Estes processos geralmente ocorrem entre 100 e $300{ }^{\circ} \mathrm{C}$ em pressões de 1 $10 \mathrm{MPa}^{30}$. Devlin e Harris publicaram um estudo em 1984, sobre a oxidação não catalítica de fenol em solução aquosa, usando oxigênio molecular como oxidante na faixa de temperatura de $150-225^{\circ} \mathrm{C}$ e pressão total de 20,69 MPa. Eles propuseram a ocorrência de uma etapa lenta de reação, devido à resistência à oxidação de compostos de baixo peso molecular (principalmente ácidos carboxílicos), formados em etapas anteriores do mecanismo de oxidação ${ }^{8}$. 
Diversos estudos detalhados sobre a cinética e o mecanismo de oxidação do fenol e fenóis substituídos em soluções alcalinas ( $\mathrm{pH}$ 9,5-13), usando oxigênio como agente oxidante, em temperaturas na faixa de $25-80{ }^{\circ} \mathrm{C}$ foram publicados na década de $70^{8}$. As ordens de reação com relação ao oxigênio e substrato foram, respectivamente, 0 e 1 para o fenol e as suas misturas, enquanto os valores de energia de ativação apresentaram-se na faixa de 5,44-54,01 KJ/ mol. O estudo mostrou que a taxa de oxidação aumenta com o aumento da alcalinidade, em conseqüência do aumento da concentração do íon fenolato do meio. Os produtos finais obtidos, durante o processo de oxidação, incluíam material polimérico, catecol, hidroquinona e ácidos carboxílicos. A seguinte ordem de reatividade foi observada entre os fenóis estudados: p-metoxifenol $>$ o-etilfenol $>$ 2,6 dimetilfenol $>$ p-clorofenol $>$ o-clorofenol $>$ fenol $>$ mclorofenol. Essas diferenças de reatividade foram explicadas pelo impedimento estérico dos substituintes na posição orto na estabilização do intermediário, tornando a taxa de reação do isômero orto mais lenta que aquela do para-metoxifenol ${ }^{8}$.

A oxidação com o ar é uma técnica bastante atrativa para o tratamento de efluentes; entretanto, condições energeticamente desfavoráveis podem ser requeridas em função do teor de matéria orgânica a ser abatida. Por outro lado, a severidade das condições de operação do sistema pode ser reduzida através do uso de sistemas catalíticos conjugados ${ }^{8}$.

\section{O processo de oxidação com peróxido de hidrogênio}

O peróxido de hidrogênio é um oxidante químico eficiente e de fácil manipulação, possuindo uma ampla área de aplicações, sobretudo no tratamento de efluentes. A partir deste período, foi largamente empregado em tratamento de efluentes aquosos ${ }^{1}$.

A oxidação de compostos fenólicos, utilizando o peróxido de hidrogênio, é mais eficiente que a oxidação que usa o oxigênio molecular como oxidante, em função das propriedades oxidantes do peróxido de hidrogênio. Adicionalmente, as condições de reação requeridas para o uso do peróxido são próximas às condições ambientais $\left(0,1-0,5 \mathrm{MPa}, \mathrm{T}<80^{\circ} \mathrm{C}\right)$, permitindo o abatimento de uma série de poluentes orgânicos sem um elevado consumo energético. Entretanto, o processo de oxidação do peróxido de hidrogênio é, atualmente, pouco utilizado de forma isolada, uma vez que sua ação pode ser potencializada pela combinação com sistemas catalíticos ${ }^{30}$.

Os chamados processos de oxidação catalítica por peróxido, do tipo CWPO ("Catalytic Wet Peroxide Oxidation"), são mais potentes que aqueles que utilizam o oxidante isoladamente. Uma série de materiais contendo ferro, cobre e molibdênio suportados em óxidos, argilas, zeólitas e polímeros estão sendo propostos como catalisadores para a oxidação de compostos fenólicos. Estes sistemas serão abordados em maiores detalhes neste trabalho.

\section{O processo de oxidação com ozônio}

O interesse no uso de ozônio, no tratamento de efluentes contendo poluentes, tem crescido bastante nas últimas décadas, com o desenvolvimento de geradores de ozônio em larga escala, com baixos custos de instalação e operação. Comparado com outros oxidantes, a água ozonizada é mais eficiente na degradação de poluentes e não é agressiva para a maioria dos organismos, uma vez que nenhum aditivo é adicionado à água. A ozonização também é amplamente utilizada no tratamento de água potável, na desinfecção bacterial, na remoção de odor e de algas e na degradação de poluentes orgânicos. Entretanto, sua aplicação em grandes volumes de efluentes industriais é restrita, em função da demanda de energia elétrica. Em função do seu poder oxidante e da ausência de produtos de decomposição perigosos, o ozônio é um agente potencial no pré-tratamento de compostos refratários que, posteriormente, poderão ser removidos através de métodos convencionais. A ozonização de compostos dissolvidos em água constitui-se em uma AOP, uma vez que são gerados radicais hidroxila a partir da decomposição do ozônio e a reação pode ser catalisada pela presença de traços de outras substâncias, como metais de transição ${ }^{31}$.

Em termos de demanda química de oxigênio, 2,3 mg de oxigênio são necessários para converter totalmente $1 \mathrm{mg}$ de fenol em dióxido de carbono e água. O consumo médio de ozônio por fenol oxidado varia de 1,37 a 2,09 mg/mg, sendo mais baixos a concentrações iniciais mais elevadas de fenol ${ }^{31}$. Além disso, o ozônio apresenta elevada reatividade com relação ao fenol em solução aquosa, em uma ampla faixa de temperatura ${ }^{32}$.

No caso dos processos baseados em ozônio, a presença de moléculas sequiestrantes de radicais livres tem um efeito significativo no desempenho da oxidação. Isto ocorre porque se requer um elevado consumo de ozônio para alcançar os níveis padrões de descarte do efluente contaminado, além de poderem levar à formação de co-produtos orgânicos mutagênicos, como os cloro aromáticos e aromáticos policondensados, dentre outros ${ }^{33}$.

A limitação por transferência de massa é um fator relevante a ser considerado no processo de oxidação por ozônio. Estes sistemas requerem a transferência das moléculas de ozônio da fase gasosa para a fase líquida, onde ocorre o ataque às moléculas orgânicas. Em muitos casos, a taxa de consumo de ozônio por unidade de volume pode ser tão elevada que a etapa de transferência de massa passa a limitar a velocidade da reação, reduzindo a eficiência do processo e elevando os custos de operação ${ }^{22}$.
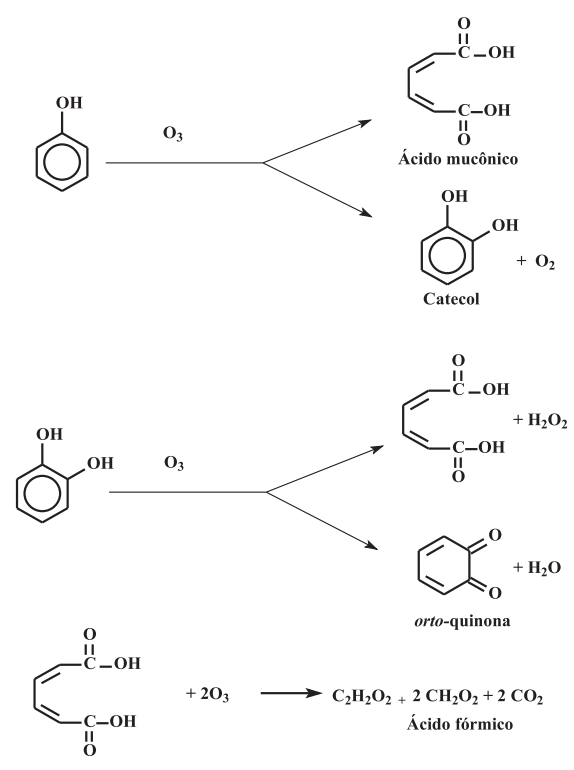

$$
\stackrel{\mathrm{O}}{\stackrel{\mathrm{O}}{\mathrm{O}}} \stackrel{+\mathrm{H}_{2} \mathrm{O}}{\longrightarrow} 2 \mathrm{CH}_{2} \mathrm{O}_{2}+2 \mathrm{CO}_{2}
$$

Figura 1. Principais reações de oxidação do fenol

As reações de oxidação de fenol com ozônio apresentam uma elevada complexidade. A reação entre o ozônio e os íons fenolatos é extremamente rápida comparada com a reação com espécies neu$\operatorname{tras}^{33}$. Assim, o ajuste do $\mathrm{pH}$ do meio reacional pode tornar o tratamento de efluente muito mais econômico, do ponto de vista do tamanho do reator e da redução do consumo de ozônio. Além disso, os sistemas reacionais compostos de inter-estágios de alimentação cáustica podem ser aplicados comercialmente, visando ao aumento da 
eficiência deste sistema. Em 1968, Eisenhauer identificou a presença de catecol e orto-quinona como produtos intermediários de reação de ozonização de fenol. O autor ainda constatou a existência de impedimentos estéricos e etapas de reação com ataques eletrofílicos. A Figura 1 apresenta as principais reações de oxidação entre o ozônio e o fenol e os respectivos produtos intermediários.

Apesar de ser bastante potente, a ozonização isolada conduz a uma mineralização limitada de compostos orgânicos e micropoluentes de água potável ou efluentes industriais. No abatimento de compostos fenólicos, observa-se apenas uma redução da TOC (Teor de carbono total em cerca de 57 a $65 \%$ dos valores iniciais ${ }^{32}$ ). Em função destas limitações, vários processos combinados de oxidação (tais como o $\mathrm{O}_{3} / \mathrm{H}_{2} \mathrm{O}_{2}, \mathrm{UV} / \mathrm{O}_{3}, \mathrm{O}_{3}$ /catalisadores etc.) vêm sendo investigados como métodos potenciais para o abatimento de compostos orgânicos em água.

\section{SISTEMAS COMBINADOS DE TRATAMENTO DE EFLUENTES}

As principais técnicas de oxidação combinadas aplicadas ao tratamento de efluentes líquidos utilizam: carvão ativado associado a oxidantes; catálise homogênea associada a oxidantes e, catálise heterogênea associada a oxidantes.

\section{Tratamento de efluentes com carvão ativado associado a oxidantes}

No sentido amplo, o termo "carvão ativado" inclui uma variedade de materiais à base de carbono, amorfos ou altamente cristalinos, com alto grau de porosidade. Esses sólidos são adsorventes únicos e versáteis, devido à sua elevada área superficial específica, estrutura microporosa, capacidade de adsorção não específica e alta reatividade superficial ${ }^{20}$.

Existe uma grande variedade de carvões ativados, disponíveis comercialmente ou sintetizados em laboratório, que exibe diferentes características a depender da matéria-prima e da técnica de ativação utilizada em sua produção.

A adsorção de fenol em carvão ativado tem sido amplamente estudada, existindo muitas isotermas disponíveis na literatura ${ }^{2-7,29}$. Entretanto, existem poucos estudos sobre a adsorção competitiva de fenol e catecol ou hidroquinona, que são de grande interesse científico. Em um desses estudos, Polaert e colaboradores investigaram a cinética de adsorção de fenol em presença de hidroquinona e catecol. Concluíram que a adsorção simultânea de fenol e seus derivados, sobre carvão ativado, ocorre principalmente em monocamadas e em sistemas com baixas concentrações de compostos orgânicos. Em concentrações mais elevadas, a interação entre as moléculas adsorvidas torna-se significante e, como conseqüência, a equação de Freundlich descreve melhor os dados experimentais que a de Langmuir. Com um único componente (adsorção simples) o carvão ativado geralmente exibe capacidade de adsorção mais elevada do fenol que do catecol ou hidroquinona, devido à maior densidade eletrônica dos anéis aromáticos não substituídos do fenol ${ }^{34,35}$.

Recentemente, os carvões ativados têm sido avaliados com sucesso como catalisadores na remoção de poluentes orgânicos em água. O uso desses catalisadores apresenta as vantagens do uso de um material de baixo custo e, ainda, possibilita a combinação da sua excelente capacidade adsortiva com suas propriedades catalíticas ${ }^{34}$. Neste caso, associa-se o processo de adsorção ao de oxidação, levando a uma maior eficiência na remoção dos poluentes.

Em 2002, Polaert estudou o processo de adsorção - oxidação em duas etapas, aplicado ao tratamento de compostos fenólicos em efluentes aquosos. O processo baseou-se no uso de carvão ati- vado como adsorvente, em uma primeira etapa e como catalisador de oxidação em uma segunda etapa, usando um reator bifuncional de leito gotejante. Empregaram-se temperaturas inferiores a 200 ${ }^{\circ} \mathrm{C}$ e 100 bar de pressão, sob fluxo de oxigênio com pressão parcial de 55 bar. A principal vantagem do sistema é a economia de energia obtida nas etapas de regeneração e oxidação, uma vez que apenas uma pequena quantidade de líquido deve ser aquecido e pressurizado para dar continuidade ao processo. Este estudo, desenvolvido em condições de velocidade espacial moderada, levou à conclusão de que o processo de adsorção/oxidação oferece boa potencialidade para o tratamento de efluentes com elevadas concentrações de fenol, sendo bastante apropriado para o tratamento de efluentes com baixas concentrações de fenol ${ }^{36}$.

$\mathrm{Na}$ literatura está descrita uma ampla variedade de aplicações dos carvões como componente de sistemas de abatimento de fenóis em efluentes aquosos, seja pela sua atuação como adsorvente ou como catalisador associado a oxidantes ${ }^{17,20,34}$. Entretanto, ainda há necessidade de estudos complementares sobre a estabilidade e suas aplicações em sistemas industriais.

\section{Tratamento de efluentes por sistemas homogêneos associados a oxidantes}

$\mathrm{O}$ sistema Fenton homogêneo clássico constitue-se de íons $\mathrm{Fe}^{+2}$ em solução de peróxido de hidrogênio, sendo um dos sistemas mais ativos para a oxidação de compostos orgânicos em água. A reação de Fenton baseia-se na transferência de elétrons entre o peróxido de hidrogênio e o metal, atuando como catalisador homogêneo ${ }^{1,37}$. A reatividade deste sistema foi inicialmente observada, em 1894, pelo pesquisador Fenton mas sua aplicabilidade só foi reconhecida em 1930, quando foi proposto o mecanismo baseado nos radicais hidroxil $\left(\mathrm{HO}^{\bullet}\right)$. O reagente Fenton pode ser empregado no tratamento de águas industriais contendo uma variedade de poluentes orgânicos, tais como fenóis, formaldeído, pesticidas, aditivos de plásticos e borrachas. O processo pode ser aplicado a efluentes aquosos, lodos e solos com uma redução da toxicidade e aumento da biodegradabilidade do sistema, assim como remoção de cor e de odor ${ }^{37}$.

As principais etapas do mecanismo de reação utilizando o reagente Fenton é apresentado pelas Equações 3 a 13. Recentemente, alguns autores têm admitido a possibilidade da existência de outros intermediários como, por exemplo, o ferro em um elevado estado de oxidação, $\mathrm{Fe}^{+4} 1$.

\section{Reações iniciais:}

$\mathrm{H}_{2} \mathrm{O}_{2} \rightleftarrows \mathrm{H}_{2} \mathrm{O}_{+} 1 / 2 \mathrm{O}_{2}$

$\mathrm{H}_{2} \mathrm{O}_{2}+\mathrm{Fe}^{+2} \rightleftarrows \mathrm{Fe}^{+3}+\mathrm{HO}^{-}+\mathrm{HO}^{\bullet}$

$\mathrm{H}_{2} \mathrm{O}_{2}+\mathrm{Fe}^{+3} \rightleftarrows \mathrm{Fe}(\mathrm{OOH})^{+2}+\mathrm{H}^{+} \rightleftarrows \mathrm{Fe}^{+2}+\mathrm{HO}_{2}+\mathrm{H}^{+}$

$\mathrm{HO}^{-}+\mathrm{Fe}^{+3} \rightleftarrows \mathrm{Fe}(\mathrm{OH})^{+2} \rightleftarrows \mathrm{Fe}^{+2}+\mathrm{HO}^{\bullet}$

Reações de propagação:

$\mathrm{HO}^{\bullet}+\mathrm{H}_{2} \mathrm{O}_{2} \rightleftarrows \mathrm{HO}_{2}^{\bullet}+\mathrm{H}_{2} \mathrm{O}$

$\mathrm{HO}_{2}^{\bullet}+\mathrm{H}_{2} \mathrm{O}_{2} \rightleftarrows \mathrm{HO}^{\bullet}+\mathrm{H}_{2} \mathrm{O}+\mathrm{O}_{2}$

$\mathrm{HO}_{2}^{\bullet}+\mathrm{HO}^{-} \rightleftarrows \mathrm{HO}^{\bullet}+\mathrm{HO}^{-1}+\mathrm{O}_{2}$

Reações de terminação

$\mathrm{Fe}^{+2}+\mathrm{HO} \rightleftarrows \mathrm{Fe}^{+3}+\mathrm{HO}^{-1}$

$\mathrm{HO}_{2} \cdot+\mathrm{Fe}^{+3} \rightleftarrows \mathrm{Fe}^{+2}+\mathrm{H}^{+}+\mathrm{O}_{2}$ 
$\mathrm{HO} \cdot+\mathrm{HO}_{2}^{\bullet} \rightleftarrows \mathrm{H}_{2} \mathrm{O}+\mathrm{O}_{2}$

$\mathrm{HO}^{\bullet}+\mathrm{HO}^{\bullet} \rightleftarrows \mathrm{H}_{2} \mathrm{O}_{2}+\mathrm{O}_{2}$

A atividade catalítica desses sistemas está associada à presença do radical hidroxila, gerado a partir da decomposição do peróxido de hidrogênio ativado por íons ferro, que são lixiviados simultaneamente e que agem como um catalisador homogêneo ${ }^{20}$.

As dificuldades na utilização do processo residem no longo tempo de contato requerido para a oxidação, assim como na dificuldade de recuperação do reagente do sistema. Atualmente, os catalisadores homogêneos estão sendo substituídos por sistemas heterogêneos constituídos por metais suportados, devido à contaminação tóxica e à necessidade de remoção dos catalisadores homogêneos da solução através de uma segunda etapa de tratamento ${ }^{38}$.

Existe um grande interesse no estudo de novos sistemas ativos que não gerem resíduos e que possuam potencial catalítico. Recentemente, tem-se investigado o uso de diferentes óxidos de ferro, substituindo o ferro solúvel através de um novo sistema Fenton heterogêneo. Como exemplo, cita-se a goetita, o hidróxido de ferro e o ferro suportado em sílica ou alumina. Entretanto, todos esses sistemas apresentaram baixas atividades à oxidação de compostos orgânicos, quando comparados aos catalisadores homogêneos ${ }^{39}$.

Recentemente, têm sido observados avanços na eficiência do processo, recorrendo-se à utilização de sistemas assistidos por radiação ultravioleta. Este aumento da eficiência é atribuído à geração de quantidades adicionais de radicais hidroxila, por fotorredução de íons férricos formados durante a reação Fenton. A fotorredução leva à regeneração dos íons ferrosos, fechando o ciclo catalítico ${ }^{38}$.

\section{Tratamento de efluentes por catalisadores heterogêneos associados a oxidantes}

Apesar da oxidação catalítica não ser uma tecnologia recente, os avanços mais significativos foram propostos nos últimos dez anos. As modificações introduzidas visavam a oxidação de compostos orgânicos para formar dióxido de carbono ou produtos que pudessem ser eliminados por tratamento biológico. Os processos catalíticos envolvendo ozônio, oxigênio, peróxido de hidrogênio ou a combinação destes têm sido objeto de uma série de estudos científicos ${ }^{1,30}$. A oxidação catalítica com peróxido de hidrogênio tem se mostrado mais eficiente que a oxidação catalítica com ar. Além disso, as condições reacionais requeridas, quando o peróxido é usado como oxidante, são mais próximas às condições ambientais (pressões 0,1-0,5 $\mathrm{MPa}$ e temperaturas inferiores a $80^{\circ} \mathrm{C}$ ). Alguns estudos usando zeólitas ou argilas contendo cobre e ferro têm mostrado um aumento significativo de atividade e estabilidade do catalisador, em meio aquoso. $\mathrm{O}$ conceito envolvido é que o aumento da eficiência do processo está associado ao aumento da concentração de compostos orgânicos próximos aos sítios de ativação do peróxido de hidrogênio, favorecendo tanto a oxidação quanto a eficiência do uso do peróxido de hidrogênio.

Os métodos de oxidação catalítica apresentam uma grande vantagem sobre os métodos de oxidação convencionais, que é a possibilidade de tratar isoladamente um único poluente, ou um grupo de poluentes. Através da escolha adequada do catalisador, é possível não somente controlar o grau da conversão dos poluentes, mas também selecionar diferentes rotas de reação, de forma a evitar a formação de poluentes secundários ${ }^{20}$.

Os catalisadores heterogêneos usados na oxidação catalítica em meio aquoso podem ser classificados em três categorias: óxidos de metais de transição; metais nobres suportados e, sais de metais e seus complexos. As aplicações baseadas em metais nobres (platina, rutênio, paládio, ródio, irídio e prata) e óxidos metálicos (manganês, cobalto, cobre, zinco, vanádio, níquel, ferro, bismuto e titânio), usando diversos suportes (alumina, dióxido de cério, dióxido de titânio, dióxido de zircônio e zeólitas), são bastante amplas e encontram-se descritas de forma detalhada na literatura ${ }^{8,38}$.

As recentes investigações científicas têm buscado o desenvolvimento de catalisadores que apresentem alta atividade na oxidação de fenóis e elevada seletividade, na geração de dióxido de carbono e água, tornando o processo reacional limpo $23,29,40$. Esses catalisadores devem apresentar, como principais propriedades, uma elevada capacidade de conversão total, estabilidade física e química em meio ácido e resistência a venenos presentes nas correntes a serem tratadas ${ }^{20}$. Algumas dificuldades devem ser superadas, com relação à estabilidade de catalisadores heterogêneos de oxidação em condições hidrotérmicas, dentre elas: a lixiviação e a sinterização do material ativo; a perda de área superficial específica do suporte; o envenenamento dos sítios ativos por eventual evolução de monóxido de carbono e, o depósito de material orgânico e inorgânico na superfície do catalisador.

Dentre os aspectos apresentados, a lixiviação do material ativo é a principal dificuldade e tem sido o aspecto mais investigado ${ }^{30,40}$. A dissolução do material ativo pode ser controlada pela escolha apropriada da fase metálica do oxidante e pelo controle do $\mathrm{pH}$, durante a reação. Vários catalisadores, baseados em óxidos metálicos ou metais preciosos suportados, foram sintetizados e testados nas últimas décadas. As misturas de óxidos metálicos de cobre, zinco, cobalto, manganês e bismuto apresentaram atividade catalítica, mas apresentaram o inconveniente de serem lixiviados. Por outro lado, os catalisadores heterogêneos baseados em metais preciosos depositados em suportes estáveis apresentaram menor tendência à lixiviação ${ }^{41}$.

Quanto à estabilidade hidrotérmica do suporte do catalisador, os óxidos de alumínio, háfnio, zircônio e titânio são conhecidos como suportes estáveis. Por outro lado, parâmetros como o pH do meio e a temperatura de calcinação são importantes para controlar a estabilidade térmica do suporte ${ }^{30}$.

O desenvolvimento de catalisadores econômicos, estáveis e ativos, que sejam eficientes na degradação de compostos orgânicos em meio aquoso, configura-se como um desafio científico e tecno-lógico. Neste contexto, os catalisadores de metais de transição e metais nobres, em suportes óxidos ou zeolíticos, têm se mostrado como mais promissores, especialmente no abatimento de fenol em efluentes ${ }^{38}$.

\section{Emprego de catalisadores baseados em óxidos metálicos associados a oxidantes}

A associação de catalisadores a oxidantes, no processo de oxidação de compostos fenólicos modelo e industriais em meio aquoso, foi investigada inicialmente com catalisadores de platina e rutênio suportados em óxidos de titânio e zircônio. Foi enfocada a reatividade dos poluentes (ácidos fórmico, oxálico e maléico) e o efeito da temperatura sobre a estabilidade destes catalisadores heterogêneos usando oxigênio molecular como oxidante. Foi observada uma completa degradação de compostos orgânicos a inorgânicos e concluiu-se que a natureza do poluente era crítica na seleção do catalisador. Os catalisadores de rutênio mostraram-se mais ativos, mas apenas a temperaturas elevadas ${ }^{41}$.

Os resultados da investigação da oxidação de fenol sobre cobre ou sobre óxido de cobre/cromita, usando reator de agitação e temperaturas moderadas $\left(127-180{ }^{\circ} \mathrm{C}\right)$, foram discutidos por Santos e colaboradores, em 2002. O oxigênio foi usado como oxidante e o efluente tratado apresentou elevadas concentrações de fenol (1200 
ppm). Em temperaturas mais baixas, observou-se um aumento da taxa de oxidação de fenol e da relação dióxido de carbono/fenol, quando se empregou uma quantidade maior de catalisador. Entretanto, em temperaturas mais elevadas, observou-se uma maior contribuição do mecanismo homogêneo na oxidação do fenol ${ }^{42}$.

Em outros trabalhos, observou-se que o uso de metais nobres, como promotores, aumenta a eficiência dos sistemas catalíticos baseados em óxidos metálicos. Hamoudi e colaboradores, estudaram a influência da adição de metais nobres (platina e prata) no desempenho dos catalisadores do tipo $\mathrm{MnO}_{2} \backslash \mathrm{CeO}_{2}$ na oxidação de fenol em meio aquoso, usando oxigênio como oxidante. Os testes foram conduzidos em temperaturas na faixa de $80-130{ }^{\circ} \mathrm{C}$, em reator do tipo autoclave, sob pressão de oxigênio. Também foi estudado o efeito sobre a desativação dos catalisadores, por depósito de carbono. Os resultados mostraram que a presença de metais nobres como promotores leva ao aumento da seletividade e à mineralização total do fenol, em condições brandas de reação ${ }^{42}$.

As informações disponíveis na literatura mostram que os sistemas catalíticos baseados em óxidos metálicos são eficazes no abatimento de poluentes orgânicos em água, incluindo os compostos fenólicos. O desempenho deste sistema catalítico é função da natureza do poluente, do tipo de óxido e das condições de reação. A sua baixa estabilidade é uma inconveniência a ser eliminada a partir de contribuições científicas futuras, visando o desenvolvimento de catalisadores comerciais.

\section{Emprego de catalisadores zeolíticos associados a oxidantes}

A zeólita ZSM-5 é o membro mais importante de uma família de zeólitas chamada pentasil, que possui alta quantidade de silício e, portanto, alta estabilidade térmica apresentando importantes aplicações como catalisadores e suportes catalíticos. Sua estrutura resulta da combinação de anéis de cinco tetraedros, formando cadeias que se combinam e formam camadas que se ligam entre si, formando um sistema poroso constituído de dois tipos de canais formados por anéis de dez membros ${ }^{41}$. Diversos metais, tais como ferro e cobre, podem ser incorporados na sua estrutura, permitindo a obtenção de materiais com propriedades pré-estabelecidas. Por exemplo, trabalhos recentes mostraram que a localização do íon ferro na estrutura zeolítica (intra ou extra rede cristalina) influencia a sua atividade de abertura do anel aromático e a seletividade na formação de dióxido de carbono e água, como produtos da oxidação de fenol ${ }^{2,3}$. Observou-se que as espécies de ferro intra-estruturais, sistemas do tipo Fe-ZSM-5, são mais seletivas à oxidação total do fenol em presença de peróxido de hidrogênio, embora as espécies extra-estruturais também apresentassem atividade catalítica.

Existem poucos trabalhos sobre a aplicação de catalisadores metálicos, à base de zeólitas do tipo ZSM-5, nas reações de abatimento de poluentes em meio aquoso. Aspectos relevantes como o entendimento do mecanismo de reação dos cátions intra e extra estrutural ainda exigem aprofundamento. Além disso, a dificuldade de elevação do teor de metais intra-estrutural na ZSM-5 pode direcionar o desenvolvimento de novos catalisadores com outros tipos de zeólitas.

\section{Emprego de catalisadores mesoposoros associados a oxidantes}

A família de silicatos mesoporosos M41S foi sintetizada pela primeira vez por cientistas da Mobil, em $1992^{43}$. Três sub-grupos foram inicialmente identificados: a fase hexagonal MCM-41, a cúbica MCM-48, e uma fase lamelar não estável. Estes materiais despertaram muito interesse na comunidade científica, devido ao seu tamanho de poro, ou distância interlamelar, que pode ser ajustado na faixa 20 a $100 \mathrm{~A}^{43,44}$. Esses sólidos possuem áreas superfi- ciais específicas elevadas e podem ser modificados pela incorporação de diferentes cátions, com propriedades ácidas ou redox.

Os materiais mesoporosos contendo titânio apresentam grande potencial de aplicação no abatimento de poluentes em efluentes líquidos. Apesar de terem sido pouco explorados, esses sistemas apresentam grande potencial de aplicação nas reações de abatimento de poluentes fenólicos em meio aquoso. Entretanto, o desenvolvimento de sistemas bimetálicos, assim como estudos sobre a estabilidade destes catalisadores são necessários visando o aumento da sua eficiência na mineralização total dos poluentes fenólicos e permitir a aplicação comercial destes sistemas.

\section{Emprego de catalisadores heterogêneos associados ao ozônio}

O uso de catalisadores tem sido apontado como uma forma de resolver os problemas de seletividade, existentes no processo de ozonização de contaminantes orgânicos em meio aquoso, aumentando o desempenho do processo ${ }^{33}$. Recentemente, diversos processos alternativos de ozonização catalisados por metais de transição foram investigados, na decomposição de compostos orgânicos. Esses processos foram classificados como: ativação do ozônio por metais em solução e, ozonização catalítica heterogênea em presença de óxidos metálicos ou metais suportados ${ }^{33}$.

Processo de ativação de ozônio por metais em solução

A presença das espécies $\mathrm{Fe}^{+2}, \mathrm{Mn}^{+2}, \mathrm{Ni}^{+2}$ ou $\mathrm{Co}^{+2}$ na forma de sulfato, durante a ozonização de efluentes aquosos, induz ao aumento da taxa de remoção de carbono total quando comparada à ozonização isoladamente. Os sulfatos de cobre ou zinco, o nitrato de prata e o trióxido de cromo são relatados como catalisadores eficientes no processo de clareamento de efluentes de produção de corantes, durante a ozonização. Um sistema semelhante, contendo sulfatos de ferro, manganês, níquel ou cobalto, foi testado no processo de ozonização de fenol sendo mais efetivo que quando conduzido na ausência destes íons ${ }^{33}$.

Processo de ativação de ozônio por catalisadores heterogêneos

A ozonização de fenol em presença de catalisador do tipo $\mathrm{Fe}^{+3}$ / $\mathrm{Al}_{2} \mathrm{O}_{3}$ foi investigada por Hayek e colaboradores, em 1989, que constataram que o catalisador promovia o aumento da remoção de carbono orgânico total (TOC), quando comparada à ozonização isolada $^{32}$. Os autores sugeriram tanto a formação de radicais livres, quanto o aumento de sítios nucleófilos de moléculas adsorvidas, para explicar a ação catalítica. Em 1996, Andreozzi e colaboradores constataram um significativo aumento da ozonização, em meio ácido, promovida pela presença de óxido de manganês ${ }^{32}$.

$\mathrm{Na}$ literatura relativa à ozonização catalítica, normalmente se focaliza a ativação de ozônio por diversos metais (ferro, manganês, níquel, cobalto, zinco, prata e cromo) em solução ou por catalisadores heterogêneos contendo metais sob várias formas (sais de metais reduzidos, óxido ou metal depositado sobre suporte). Estes compostos são capazes de aumentar a eficiência do ozônio na remoção de diferentes compostos orgânicos em meio aquoso ${ }^{32}$.

Apesar do número crescente de dados que demonstram a eficiência da ozonização catalítica, se faz necessário um maior conhecimento em alguns aspectos. A respeito dos aspectos fundamentais, é necessário elucidar o mecanismo de reação de ozônio com metais reduzidos, identificar e quantificar os subprodutos de oxidação em solução e na superfície do catalisador e o efeito de alguns parâmetros de reação como $\mathrm{pH}$, temperatura e presença de sequiestrantes de radicais livres. Quanto ao aspecto prático, é importante se conduzir estudos econômicos sobre a vida útil do catalisador e sobre as condições para aumento de escala do processo. 


\section{MECANISMOS DE REAÇÃO DA OXIDAÇÃO DE FENOL EM ÁGUA}

Comparativamente aos inúmeros estudos disponíveis sobre mecanismos de oxidação de compostos orgânicos puros, existem na literatura poucos conceitos mecanísticos sobre a oxidação catalítica de compostos fenólicos em solução aquosa. Uma das linhas mais aceitas atualmente foi proposta por Sadana e colaboradores, em $1974{ }^{41}$. Os autores constataram que a oxidação catalítica de compostos fenólicos em solução aquosa, usando óxido de cobre como catalisador, ocorre através do mecanismo de radicais livres, em concordância com os resultados obtidos na oxidação de compostos puros. A reação envolve uma etapa de iniciação sobre a superfície do catalisador, seguida de propagação homogênea ou heterogênea.

Em 1992, Pintar complementou esse estudo quando identificou as etapas de reação que levam à formação de polímeros ${ }^{41}$. Estes compostos são formados pelas duas reações que ocorrem em fase líquida: etapa inicial de polimerização do aldeído a fenol e a polimerização da molécula de aldeído. Esta polimerização homogênea reduz significativamente a extensão da oxidação total, sendo que apenas 50-60\% do teor total de carbono é transformado em dióxido de carbono, através do mecanismo de reação heterogênea. Adicionalmente, concluíu que a oxidação catalítica de fenol em solução aquosa é um caso de combinação de um mecanismo redox e de radical livre heterogêneo. O catalisador está associado à função de ativador de ambos os reagentes, fenol e oxigênio. Cada uma destas etapas requer diferentes sítios ativos na superfície do catalisador. Acredita-se que o fenol é adsorvido exclusivamente na superfície do sítio metálico e é transformado em radicais fenoxila, através de uma reação redox. Este processo de iniciação homolítico, de transferência de um elétron em que aparecem radicais livres, foi também proposto por muitos autores ${ }^{41}$.

O modelo cinético proposto por Santos para a reação considera a hidroxilação de fenol a hidroquinona e catecol, com uma oxidação posterior de diidroxilbenzenos a benzoquinonas ${ }^{44}$. Os intermediários observados foram os ácidos maléico, oxálico, fórmico e acético. Este modelo foi validado pelo mesmo autor em $2005^{45}$ e a espécie cobre/oxalato iônico foi introduzida como intermediário da reação. A Figura 2 apresenta as rotas de reação de oxidação proposta por Santos, em 2005.

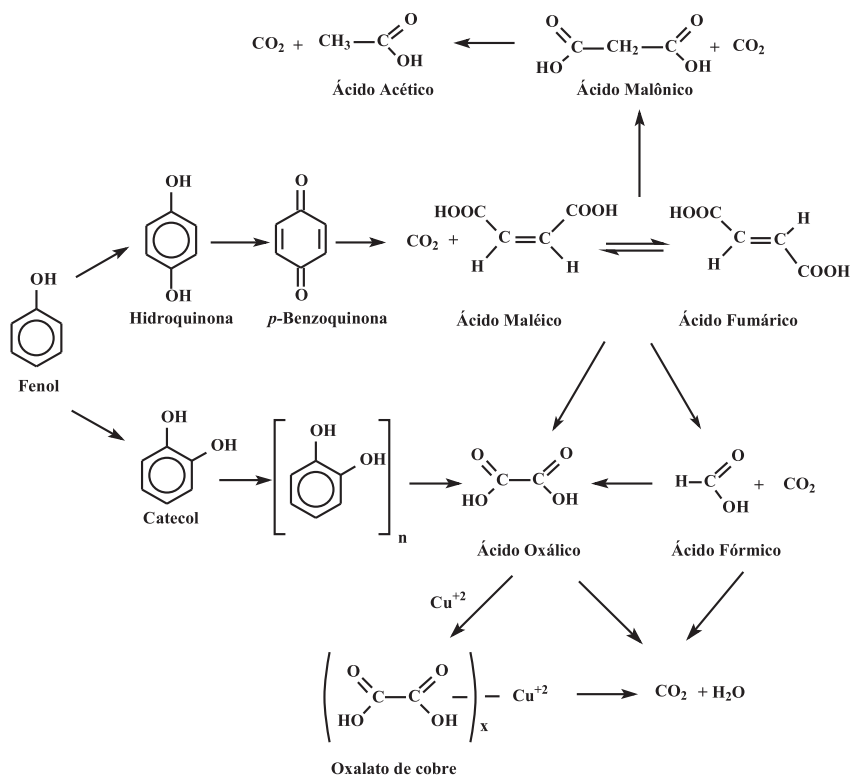

Figura 2. Etapas de reação para oxidação de fenol com óxido de cobre
Observou-se a influência de variáveis como temperatura, pressão de oxigênio e concentração de catalisadores, na formação de diferentes intermediários ${ }^{45,46}$. A diferença entre a rota proposta e o mecanismo estabelecido anteriormente refere-se à oxidação de catecol e hidroquinona. Os produtos das reações de oligomerização e polimerização só foram detectados em baixas concentrações. Os autores concluíram que a oxidação do fenol segue um mecanismo de radical livre com um período de indução que diminui com o aumento da concentração do catalisador comercial, sendo a oxidação de fenol a etapa determinante da velocidade da reação. Notouse, também, que os intermediários se oxidaram mais rapidamente que o fenol.

De forma semelhante ao sistema com oxigênio, nenhum mecanismo completo foi proposto, até então, para o sistema reacional de oxidação do fenol com ozônio como oxidante. Apenas duas sugestões de mecanismos foram apresentadas. Na primeira delas, o catalisador se comportaria apenas como adsorvente sendo, neste caso, o ozônio e o radical hidroxila as espécies oxidantes e a ação do metal não seria bem entendida. No segundo mecanismo, o catalisador promoveria a reação entre o ozônio e os compostos orgânicos adsorvidos. Inicialmente, o ozônio oxidaria o metal formando o radical hidroxila que, por sua vez, oxidaria a molécula orgânica. As etapas de reação, com transferência de elétrons, permitiriam a redução do sítio metálico e o fechamento do ciclo catalítico ${ }^{33}$.

A análise dos dados disponíveis sobre o mecanismo de oxidação de fenol leva à constatação de que a reação ocorre tanto na fase homogênea, quanto na heterogênea e que uma parcela importante, que é função da extensão da lixiviação do metal ativo, ocorre na fase líquida.

\section{CONCLUSÕES}

O interesse científico e comercial pela catálise ambiental expandiu-se significativamente, nas duas últimas décadas, devido ao aumento contínuo das restrições legais sobre a qualidade das emissões. Cada vez mais, surgem demandas pelo desenvolvimento de tecnologias de tratamento e remediação de água e a catálise pode ser as peça chave neste desenvolvimento.

Os efluentes industriais, como os provenientes das refinarias de petróleo, indústrias petroquímicas e coquearias, entre outros, freqüentemente contêm compostos fenólicos que são tóxicos ao ambiente aquático e ao homem. Estes compostos são tratados convencionalmente através de processos biológicos, de extração e adsorção, dentre outros. Entretanto, estas técnicas apresentam limitações para aplicação em sistemas de concentrações intermediárias e em presença de multicomponentes fenólicos, além de representarem um elevado custo de tratamento. Dessa forma, o uso de tecnologias avançadas de oxidação catalítica vem se consolidando como uma das tendências de desenvolvimentos futuros em catálise, juntamente com a fotocatálise.

O processo de oxidação avançado (AOP) envolve o uso de agentes oxidantes como oxigênio, ozônio, peróxido de hidrogênio, isoladamente ou combinados, em associação com catalisadores. Em todos os casos, os AOP's apresentam em comum a capacidade de gerar radicais hidroxila de elevada reatividade que exibem, entretanto, uma baixa seletividade. O uso de catalisadores específicos, baseados em metais de transição como titânio, vanádio, ferro, manganês, cobre e cromo, incorporados a suportes como óxidos, zeólitas e mesoporosos, tem sido sugerido como forma de resolver os problemas de seletividade, aumentando a eficiência dos AOP's.

Entretanto, a baixa estabilidade dos sistemas catalíticos ainda constitui uma inconveniência a ser superada a partir de contribuições científicas. Outras metas a serem alcançadas são o aumento 
da eficiência na redução do teor de carbono orgânico, assim como o aumento da seletividade na mineralização dos compostos poluentes.

Dentre as técnicas de abatimento apresentadas, aquelas que apresentam maior potencialidade para aplicação industrial são os processos de oxidação avançado e, dentre eles, os processos que associam catálise heterogênea a oxidantes, apresentam uma aplicabilidade a curto prazo, enquanto os processos que utilizam a fotocatálise se apresentam como viáveis a longo prazo, em função do desenvolvimento da tecnologia para larga escala.

A seleção da técnica específica para uso no processo de abatimento de fenol em efluentes industriais é função das limitações do sistema em estudo e dos recursos disponíveis no processo industrial.

\section{REFERÊNCIAS}

1. Pera Titus, M.; Garcia-Molina, V.; Baños, M.A; Giménez, J.; Esplugas, S.; Appl. Catal., B 2004, 47, 219.

2. Tatibouet, J-M.; Studies in Surface Science and Catalysis 2000, 130, 749.

3. Phu, N.; Nguyen, N. H.; Tran, K. T.; Appl. Catal., B 2001, 34, 267.

4. Zhou, G. M.; Fang, H. P.; Bioresour. Technol. 1997, 61, 47.

5. Guerra, R.; Chemosphere 2001, 44, 1737.

6. Gennaro, M. C.; Pittavino, S.; J. Environ. Sci. Health, Part A: Toxic./ Hazard. Subst. Environ Eng. 1997 32, 735.

7. Colarieti, M. L.; Toscano, G.; Greco, G.; Water Res. 2002, 36, 3015.

8. Mishra, V.S.; Kumar, V.; Mohajari, V.; Joshi, J. T. B.; Ind. Eng. Chem. Res. 1995, 34, 2 .

9. Centi, G.; Ciambelli, P.; Perathones, S.; Russo, P.; Catal. Today 2002, 753, 15.

10. Kojima, T.; Nishijima, K.; Matsukata, M.; J. Membr. Sci. 1995, 102, 43.

11. Ghose, M. K.;Water Res. 2002, 36, 1127.

12. Froment, G. F.; Chem. Eng. Sci. 1981, 36, 1271.

13. Morrison, R.; Boyd, R.; Química Orgânica, $11^{2}$ ed, Fundação Calouste Gulbenkiean, 1994, p. 146-147.

14. Albright, L. F.; Crynes, B. L.; Corcoran, W. H.; Academic Press, 1983, p. 271.

15. McConnel, C. F.; Head, B. D.; Academic Press, New York, 1983.

16. Tsang, W.; Ind. Eng. Chem. Res. 1992, 31, 3.

17. Matatov-Meytal,Y.; Sheintuch, M.; Ind. Eng. Chem. Res. 1997, 36, 4374.

18. Ikehata, K.; Nicell, J. A.; Bioresour. Technol. 2000, 74, 191.

19. Tiburtius, E. R. L.; Peralta-Zamora, P.; Quim. Nova 2004, 27, 441.
20. Matatov-Meytal, Y.; Sheintuch, M.; Ind. Eng. Chem. Res. 1998, 37, 309 21. László, K.; Nagy, L. G.; Carbon 1996, 35, 593.

22. Wankat, P. C.; Elsevier Science Publishing Co., Inc. 1988, p. 515-542.

23. Andreozzi, R.; Marotta, R.; J. Harzard. Mater. 1999, B69, 303.

24. Alverez-Gallegos, A.; Pletcher, D.; Electrochim. Acta 1999, 44, 2483.

25. Villasenõr, J.; Reyes, P.; Pecchi, G.; Catal. Today 2002, 76, 121.

26. Saksono, N.; Slamet, P.; 18th North American Catalysis Society Meeting, Mexico, 2003

27. Gernjak, W.; Krutzler, T.; Glaser, A.; Malato, S.; Caceres, J.; Bauer, R.; Fernández-Alba, A. R.; Chemosphere 2003, 50, 71.

28. Grzechulska, J.; Morawski, A. W.; 18 th North American Catalysys Society Meeting, Mexico, 2003.

29. Hermann, J. M.; Guillard, C.; Disdier, J.; Lehourt, C.; Malato, S.; Blanco, J.; Appl. Catal., B 2002, 35, 281.

30. Barrault, J.; Bouchoule, C.; Appl. Catal., B 1998, 15, 269.

31. Chen, J. W.; Hui, C.; Keller, T.; Smith, G.; Water - Physical Chemical Wastewater Treatment, AIChE Syposium Series, 1976.

32. Anderson, A.; Water-Physical, Chemical Wasterwater Treatment, AICHE Symposium Series, 1976.

33. Rivera-Utrilla, J.; Sánchez-Polo, M.; Appl. Catal., B 2002, 39, 319

34. Ahumada, E.; Lizama, H.; Orellana, F.; Suárez, C.; Huidobro, A.; Sepúlveda-Escribano, A.; Rodriguez-Reinoso, F.; Carbon 2002, 40, 2827.

35. Oliveira, L. C. A.;Silva, C. N.; Lago, R. L. M.; Anais do $12^{\circ}$ Congresso Brasileiro de Catálise, 2003.

36. Polaert, I.; Wilhelm, A. M.; Delmas, H.; Chem. Eng. Sci. 2002, 57, 1585.

37. Paczésniak, T.; Sobkowiak, A.; J. Mol. Catal. A: Chem. 2003, 194, 1.

38. Silva, A. M. T.; Marques,R. R. N; Quinta-Ferreira, R. M.; Appl. Catal., B 2004, 47, 269

39. Costa, R. C,; Santos, F. A.; Silva, L. A.; Ardisson, J. D.; Yoshida, M. I.; Carvalho, C. F.; Lago, R. M.; Anais do $12^{\circ}$ Congresso Brasileiro de Catálise 2003.

40. Parvulescu, V.;Anastasescu, C.; Constantin, C.; Su, B. L.; Stud. In Surf. Science and Catalysis, 2002, 142, 1213.

41. Pintar, A.; Catal. Today 2003, 77, 451

42. Hamoudi, S.; Sayari, A.; Belkacemi, K.; Bonneviot, L.; Larachi, F.; Catal. Today 2000, 62, 379.

43. Kaeding, W.; Mobil Oil Corp., U.S. pat. 4,016,219 1977.

44. Santos, A.; Yustos, P.; Quintanilla, A.; Rodriguez, S.; Garcia-Ochoa, F.; Appl. Catal., B 2002, 39, 97.

45. Santos, A.; Yustos, P.; Quintanilla, A.; Ruiz, G.; Garcia-Ochoa, F.; Appl. Catal., B 2005, 61, 323.

46. Quintanilla, A.; Casas, J. A.; Zazo, J. A.; Mohedano, A. F.; Rodríguez, J. J.; Appl. Catal., B 2006, 62, 115. 